\title{
Deep Vein Thrombosis in a Patient of Extrapulmonary Tuberculosis
}

\author{
Rupak Chatterjee ${ }^{1}$ Sumanta Sinha ${ }^{1} \quad$ Kumkum Sarkar $^{1} \quad$ Debananda Gonjhu ${ }^{1} \quad$ Sekhar Pal ${ }^{1}$ \\ Netai Pramanik ${ }^{1}$ \\ 1Department of Tropical Medicine, School of Tropical Medicine, \\ Kolkata, West Bengal, India

\begin{abstract}
Address for correspondence Kumkum Sarkar, Department of Tropical Medicine, School of Tropical Medicine, 108, CR Avenue, Kolkata 700073, West Bengal, India

(e-mail: dr.kumkum.sarkar@gmail.com).
\end{abstract}

Int J Recent Surg Med Sci 2022;8:59-61.
Abstract
Keywords
- colonic tuberculosis
- complication
- deep vein thrombosis

Among the various complications reported to be caused by tuberculosis (TB), thrombogenic potential is a rare entity. Here, we report a case of colonic tuberculosis in a 30-year-old male who developed left upper limb deep vein thrombosis (DVT). Ruling out other possible causes of DVT and improvement of the affected limb with antitubercular drugs led to conclusion that DVT was most probably due to TB.

\section{Introduction}

India is one of the countries with highest tuberculosis (TB) burden of the world. It is caused by Mycobacterium tuberculosis, an acid-fast bacilli with ability to affect almost all organs of human body. The complications of TB are bronchiectasis, calcification, fibrosis, end-stage lung disease, pleural effusion, pleural thickening, meningitis, Addison's crisis, disseminated intravascular coagulation and many more. The prevalence of deep vein thrombosis (DVT) in pulmonary TB patients is estimated to be 3 to $4 \%{ }^{1}$ Studies report a correlation between TB and DVT. ${ }^{2}$ As treatment for TB is widely available, clinicians must be well aware to think of TB as a cause for DVT so that it is not missed.

\section{Case Report}

A 30-year-old male was admitted with complain of pain in abdomen along with rectal bleeding for last 6 months. This was associated with significant loss of weight, anorexia, nausea, and low grade, intermittent fever. There was no other complaint. There was no $\mathrm{H} / \mathrm{O}$ addiction or any high-risk sexual behavior. On clinical examination, he had pallor, abdomen was tender with no significant organomegaly.
He underwent colonoscopy which revealed presence of colonic stricture and biopsy done from the stricture which cryptitis with ulceration, epithelioid cell granuloma, and Langhans giant cells with impression of granulomatous lesion favoring Koch's etiology ( - Fig. 1). His routine blood tests revealed severe anemia (Hb 5.6 g\%), leukocytosis (TLC$11,800 / \mathrm{mm}^{3}$, N70,L28), hypoalbuminemia with raised ALP levels, hyponatremia, and normal kidney function tests. His sputum CBNAAT was negative. There was no other focus of infection. Accordingly based on the findings, he was diagnosed as colonic TB and ATD (antitubercular drugs) was initiated along with tablet prednisolone.

Subsequently during his stay in our hospital, he developed swelling with pain and discoloration of his left upper limbclinically diagnosed as left upper limb DVT. His USG Color Doppler showed DVT affecting left cephalic, basilic, axillary, and distal part of subclavian veins with gross subcutaneous tissue edema. So, tab prednisolone was stopped and he was put on acitrom therapy. His CT angiogram was also done confirming diagnosis of DVT ( - Fig. 2). But subsequently, he developed malena and acitrom was kept on hold. His serology was nonreactive for HIV, hepatitis B and C. His anti-nuclear antibody (ANA) with ANA profile, anti-neutrophil cytoplasmic antibody (ANCA) were negative and C3,C4 level
DOI https://doi.org/ 10.1055/s-0041-1734212 ISSN 2455-7420
(C) 2021. Medical and Surgical Update Society.

This is an open access article published by Thieme under the terms of the Creative Commons Attribution-NonDerivative-NonCommercial-License, permitting copying and reproduction so long as the original work is given appropriate credit. Contents may not be used for commercial purposes, or adapted, remixed, transformed or built upon. (https://creativecommons.org/licenses/by-nc-nd/4.0/).

Thieme Medical and Scientific Publishers Pvt. Ltd. A-12, 2nd Floor, Sector 2, Noida-201301 UP, India 

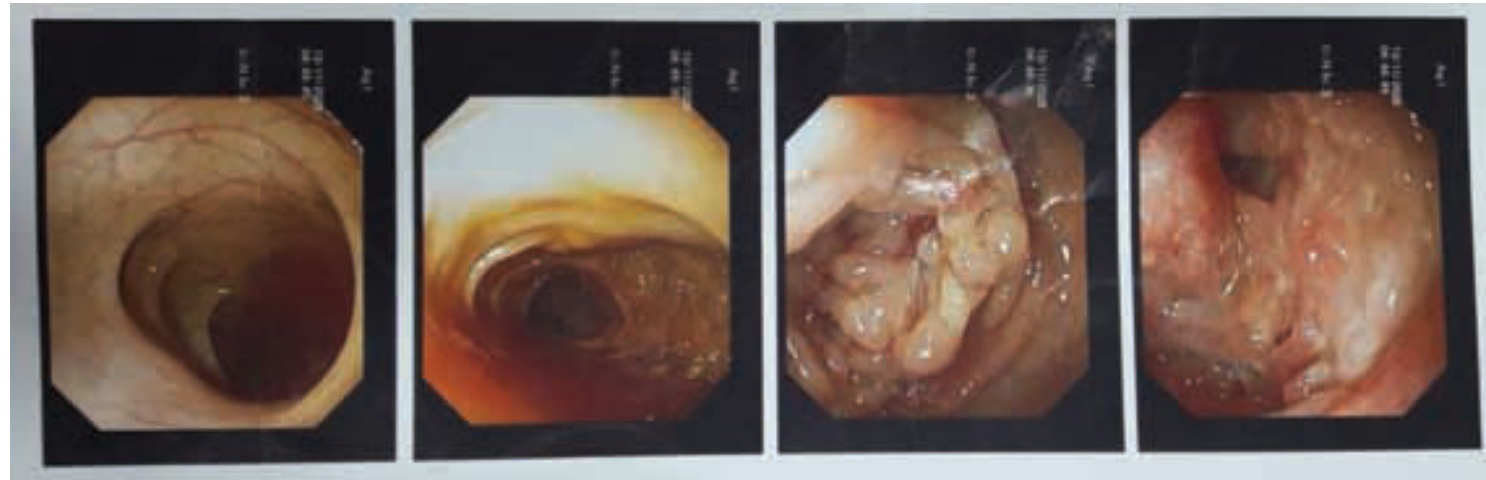

Fig. 1 Colonoscopy images showing non-negotiable concentric stricture in proximal portion of transverse colon, mucosa showing erythema, ulceration, and cobblestoning.

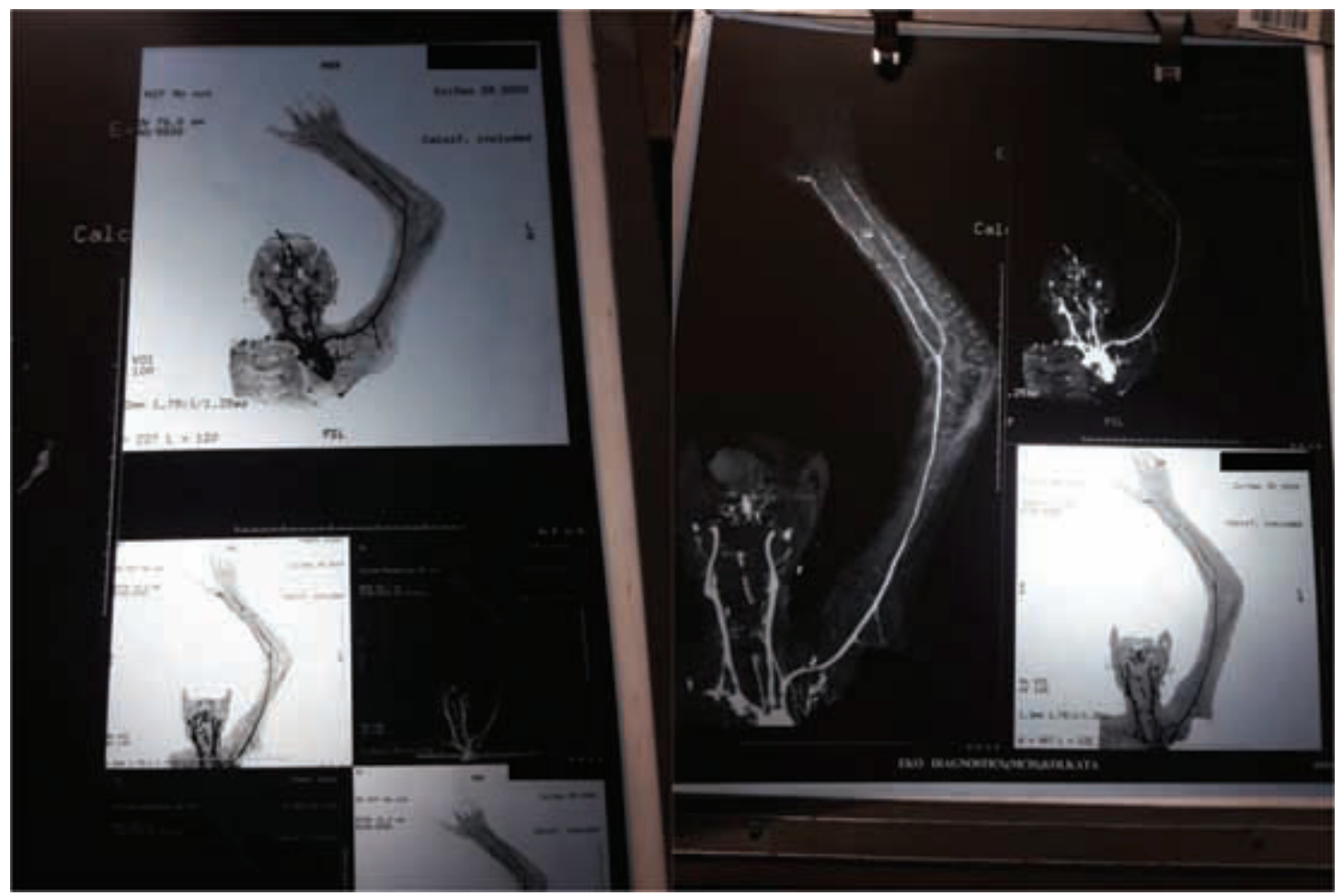

Fig. 2 CT angiogram left upper limb vessels. CT, computed tomography.

were normal. During the course of treatment with only ATD, his DVT condition started improving and there was gradual resolution of his left upper limb swelling.

\section{Discussion}

TB can manifest as local limited to single organ involvement as well as disseminated TB. ${ }^{3,4}$ Its complications depend on virulence of the organism as well as host's immune status and its responsiveness. DVT is a hematological complication of TB which has rarely been reported. ${ }^{5,6}$ DVT is caused by endothelial dysfunction, venous stasis, or a hypercoagulable state. ${ }^{78}$ Activation of mononuclear cells in TB leads to increased liberation of cytokines which have proinflammatory effect and causes endothelial dysfunction rendering it thrombogenic. TB causes increase in fibrinogen levels while decreasing levels of antithrombin III, and protein C. The bacillus may also cause direct endothelial injury. All these factors may contribute to the development of DVT in TB. ${ }^{1,2,9,10,11}$

In our patient, no other predisposing factor of DVT could be found other than TB. There was no history of any trauma, surgery, prolonged immobilization, neither there was any history of recurrent thrombosis, any bleeding disorder, or valvular heart disease. His ANA with profile, ANCA were negative with normal $\mathrm{C} 3, \mathrm{C} 4$. Moreover, responsiveness to ATD points toward TB as the etiology of unprovoked DVT. Mortality is higher in cases which are diagnosed late due to increased incidence of complications as well as advancement of the disease. ${ }^{12}$ This case report highlights the importance of consideration of TB in cases of DVT when cause remains uncertain, particularly in a country with high $\mathrm{TB}$ burden. 


\section{Conflict of Interest}

None declared.

\section{References}

1 Turken O, Kunter E, Sezer M, et al. Hemostatic changes in active pulmonary tuberculosis. Int $\mathrm{J}$ Tuberc Lung Dis 2002;6(10):927-932

2 Suárez Ortega S, Artiles Vizcaíno J, Balda Aguirre I, et al. Tuberculosis as risk factor for venous thrombosis. Med Interna 1993;10(8):398-400

3 Kim HY, Song KS, Goo JM, Lee JS, Lee KS, Lim TH. Thoracic sequelae and complications of tuberculosis. Radiographics 2001;21(4):839-858, discussion 859-860

4 Wang JY, Hsueh PR, Lee LN, et al. Mycobacterium tuberculosis inducing disseminated intravascular coagulation. Thromb Haemost 2005;93(4):729-734

5 Keeling AN, Costello R, Lee MJ. Rasmussen's aneurysm: a forgotten entity? Cardiovasc Intervent Radiol 2008;31(1):196-200
6 Cervera R, Asherson RA, Acevedo ML, et al. Antiphospholipid syndrome associated with infections: clinical and microbiological characteristics of 100 patients. Ann Rheum Dis 2004;63(10):1312-1317

7 Brotman DJ, Deitcher SR, Lip GY, Matzdorff AC. Virchow's triad revisited. South Med J 2004;97(2):213-214

8 Horowitz N, Brenner B. Thrombophilia and cancer. Pathophysiol Haemost Thromb 2008;36(3-4):131-136

9 Lang IM, Mackman N, Kriett JM, Moser KM, Schleef RR. Prothrombotic activation of pulmonary arterial endothelial cells in a patient with tuberculosis. Hum Pathol 1996;27(4):423-427

10 Robson SC, White NW, Aronson I, Woollgar R, Goodman H, Jacobs P. Acute-phase response and the hypercoagulable state in pulmonary tuberculosis. Br J Haematol 1996;93(4):943-949

11 Naithani R, Agrawal N, Choudhary VP. Deep venous thrombosis associated with tuberculosis. Blood Coagul Fibrinolysis 2007;18(4):377-380

12 Saini R, Mishra A, Gupta KK, Kallani M. Deep vein thrombosis in patient with pulmonary tuberculosis: a rare and interesting causative link? Int J Adv Med 2019;6:542-546 